\title{
A VARIAÇÃO NA CONCORDÂNCIA VERBAL DE TERCEIRA PESSOA DO PLURAL EM FLORIANÓPOLIS*
}

\author{
THE VARIATION IN THIRD-PERSON PLURAL SUBJECT/VERB AGREEMENT IN \\ FLORIANÓPOLIS
}

Isabel de Oliveira e Silva Monguilhott

Professora do Departamento de Metodologia de Ensino

Centro de Ciências da Educação

Universidade Federal de Santa Catarina

monguilhott@hotmail.com

\begin{abstract}
RESUMO: Neste artigo, apresentamos os resultados de uma análise da variação na concordância verbal de terceira pessoa do plural na fala de informantes de Florianópolis (SC). O corpus para esta pesquisa é composto de 16 entrevistas realizadas em comunidades florianopolitanas urbanas e não urbanas. Os resultados gerais apontam que a não concordância é verificada, na perspectiva linguística, em contextos de verbos menos salientes, com o último elemento antecedente com marcas de plural, com sujeito posposto marcado com traço [humano]. Na perspectiva social, a não marcação é observada na fala de informantes menos escolarizados, nativos da Costa da Lagoa, uma das localidades consideradas menos urbana e mais afastada das regiões centrais da cidade.
\end{abstract}

PALAVRAS-CHAVE: Concordância verbal. Variação linguística. Dialetologia pluridimensional.

ABSTRACT: In this paper, we present the results of an analysis of the variation in third person plural verb agreement in speech data provided by speakers from Florianópolis. The corpus of this research is composed of sixteen interviews gathered in urban and nonurban communities from Florianópolis. The general results show that non-marking agreement is verified, in linguistic perspective, in less salient verbs, when the antecedent element presents plural marks, and when postponed subject is marked with [-human] feature. In social perspective, non-marking agreement is observed in the speech of informants with less degree of schooling, natives from Costa da Lagoa, one of the zones considered less urban and more distant from the central areas of the city.

KEYWORDS: Verb agreement. Language variation. Pluridimensional dialectology.

\footnotetext{
* Este artigo resulta de um recorte da minha tese de doutorado defendida em 2009, orientada pela Professora Doutora Izete Lehmkuhl Coelho, que investigou a concordância verbal de terceira pessoa do plural em amostras sincrônicas e diacrônicas do PB de Florianópolis e do PE de Lisboa. Aqui recortamos apenas a investigação referente à amostra sincrônica do PB de Floranópolis/SC.
} 


\section{INTRODUÇÃOO}

A concordância verbal de terceira pessoa do plural no português brasileiro (PB) vem sendo estudada, à luz da sociolinguística variacionista, desde a década de 70, com o trabalho precursor de Lemle e Naro (1977).

Neste artigo, resultado da minha pesquisa de doutorado, cujo quadro teórico se constitui de um lado, de pressupostos da Teoria da Variação e Mudança Linguística (TVML), (cf. WEINREICH, LABOV e HERZOG, 1968; LABOV, 1972, 1994) e de, outro lado, de pressupostos da Dialetologia Pluridimensional (cf. RADTKE e THUN, 1996; THUN, 1998; BELLMANN, 1999), pretendemos investigar e mapear o fenômeno da concordância verbal de terceira pessoa do plural no PB em uma amostra sincrônica.

A TVML aborda a estrutura e evolução da linguagem num contexto social da comunidade de fala, partindo do pressuposto de que a variação na fala de indivíduos pertencentes a uma mesma comunidade linguística é sistematizada, i.e., toda variação é condicionada por fatores de ordem diversa, e a mudança linguística resulta desta variação.

A perspectiva da dialetologia pluridimensional, adotada neste trabalho, visa à investigação da variação da língua na dimensão geográfica e também na dimensão social. Acreditamos que essa nova perspectiva da dialetologia permite um trabalho associado à perspectiva da sociolinguística variacionista para a investigação da heterogeneidade linguística, já que, como Thun (1998) evidencia, a dialetologia pluridimensional é formada pela superfície dialetológica horizontal (variação geográfica) e pelo eixo vertical da sociolinguística (variação social), analisando, então, os planos vertical e horizontal da linguagem e suas relações.

Dentro dessa perspectiva teórica, temos como objetivos (i) enfatizar os aspectos metodológicos envolvidos na coleta de dados da amostra sincrônica de fala investigada neste trabalho; (ii) analisar grupos de fatores linguísticos e extralinguísticos que possam estar condicionando a variação na concordância verbal de terceira pessoa do plural no PB de Florianópolis/SC.

Levantamos como hipótese geral a de que a variação do fenômeno da concordância verbal é condicionada muito mais por grupos de fatores linguísticos do que extralinguísticos (cf. MONGUILHOTT, 2001).

Nosso artigo está assim organizado: na próxima seção definimos os procedimentos metodológicos adotados na pesquisa, na seção 3 apresentamos a análise e a discussão dos resultados, e, por fim, na seção 4 tecemos algumas considerações.

\section{PROCEDIMENTOS METODOLÓGICOS}

Definimos, nesta seção, os procedimentos metodológicos adotados para a pesquisa. Inicialmente, definimos a amostra da pesquisa, e, em seguida, apresentamos a variável dependente e as variáveis independentes controladas.

A amostra para a pesquisa compreende um corpus de dados sincrônicos coletado em quatro localidades de Florianópolis: Ribeirão da Ilha e Costa da Lagoa, na zona não urbana, Ingleses e Centro, na zona urbana e a coleta foi realizada durante o segundo semestre de 2006 e o primeiro semestre de 2007, ao longo do meu curso de doutorado. 
Todas as entrevistas foram realizadas pela pesquisadora. Os assuntos levantados durante as entrevistas foram família, trabalho, lazer, estudo, redes sociais e situações de risco. As entrevistas foram gravadas em aparelho digital e armazenadas através do programa Audacity. Os dados foram coletados a partir de escutas realizadas com o auxílio do programa de áudio.

Os informantes que constituem a amostra da pesquisa foram estratificados de acordo com idade e escolaridade. Para cada ponto selecionado temos quatro informantes, dois deles com idade entre 15 e 36 anos e dois com idade entre 45 e 76 anos, dois deles com ensino fundamental e dois com ensino superior.

Foram analisados todos os dados de construções que apresentavam variação na concordância verbal de terceira pessoa, extraídos de cada uma das dezesseis entrevistas que apresentaram duração média de cinquenta minutos.

Para que pudéssemos verificar a influência dos fatores linguísticos e sociais no fenômeno em estudo, os dados coletados foram codificados e analisados estatisticamente com o auxílio do programa Goldvarb (Robinson et al., 2001).

Estabelecemos como variável dependente em nosso estudo a marcação/não marcação da concordância verbal de terceira pessoa do plural. Buscando verificar os contextos favorecedores para cada uma das variantes, selecionamos os seguintes grupos de fatores linguísticos e extralinguísticos ou variáveis independentes. Os grupos de fatores linguísticos: saliência fônica, paralelismo formal, tipo de verbo, posição do sujeito em relação ao verbo, traço humano no sujeito e tipo de sujeito. Os grupos de fatores extralinguísticos - sociais: sexo, idade/escolaridade e redes sociais, - geográficos: diatopia e diazonalidade.

\section{ANÁLISE E DISCUSSÃO DOS RESULTADOS}

Nesta seção, apresentamos os resultados obtidos na análise dos dados. Inicialmente, apresentamos os resultados referentes às variáveis selecionadas pelo Goldvarb levando em conta a caracterização feita e as hipóteses levantadas para as variáveis.

A partir da amostra investigada, obtivemos um total de 794 dados de variação na concordância verbal (CV), com 640 dados apresentando marcas de plural nos verbos, correspondendo a $80,6 \%$ da amostra, e 154 dados, $19,4 \%$ do total, com marcas zero de plural nos verbos.

Em relação ao mapeamento da variação na concordância encontrada em cada uma das localidades do PB de Florianópolis/SC investigadas, podemos observar o mapa 1 a seguir que traz os resultados da frequência de uso da CV na fala de cada informante que faz parte da amostra investigada. 


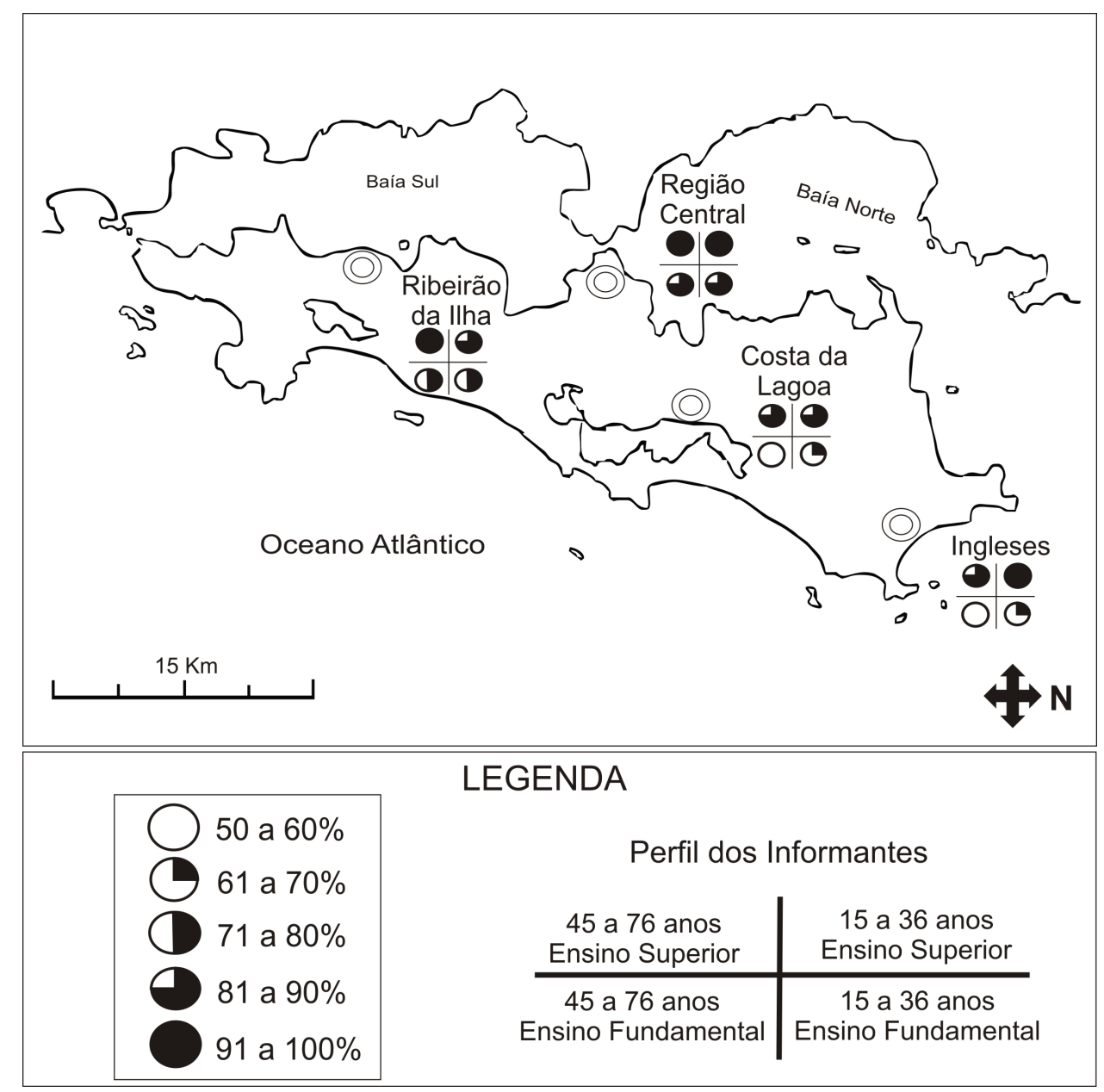

Mapa 1: Distribuição da marcação da concordância verbal no PB de Florianópolis/SC

(Fonte: MONGUILHOTT, 2009, p. 114)

\subsection{Variáveis linguísticas}

As seguintes variáveis linguísticas foram selecionadas de acordo com a ordem de relevância estabelecida pelo Goldvarb ${ }^{1}$ : saliência fônica, paralelismo formal, posição do sujeito em relação ao verbo e traço humano no sujeito. Vamos agora aos resultados e à discussão das variáveis linguísticas.

\subsubsection{Saliência fônica}

Este grupo de fatores foi estabelecido em função de dois critérios de acordo com Naro (1981): (1) presença ou ausência de acento na desinência e (2) quantidade de material fônico que diferencia a forma singular da forma plural. A partir do primeiro critério, estabeleceramse dois níveis de saliência e em cada nível apresentavam-se três categorias, salientando a diferenciação do material fônico da relação singular/plural.

\footnotetext{
${ }^{1}$ Considerando todas as variáveis controladas, o Programa Goldvarb (2001) estabeleceu a seguinte ordem de relevância: saliência fônica, paralelismo formal, posição do sujeito em relação ao verbo, idade/escolaridade, traço humano do sujeito e diatopia. A variável social idade/escolaridade e a variável geográfica diatopia que foram selecionadas serão discutidas posteriormente.
} 
- Nível 1: oposição não-acentuada:

1. não envolve mudança na qualidade da vogal na forma plural;

(1) a. Eles não consegue alcançar nosso ritmo, né? (PBRIMJS13) ${ }^{2}$

b. Aí eles não conseguem ter um bom rendimento (PBRIMJS13)

2. envolve mudança na qualidade da vogal na forma plural;

(2) a. Os poste era tudo sanguessuga que a gente fincava (PBRIMVF03)

b. As rede dele eru uma, eu fazia, abria uma boca e a gente botava (PBRIMVF03)

3. envolve acréscimo de segmentos na forma plural;

(3) a. Só que eles diz que eu tenho que trabalhá pra pagá (PBINMJF10)

b. Ah, uns dizi que é porque ele foi demitido (PBINMJF10)

- Nível 2: oposição acentuada:

1. envolve apenas mudança na qualidade da vogal na forma plural;

(4) a. As pessoa que vai pr'ali, sai dali, vai tomá cachaça e fazê até algum mal (PBCLMVF07)

b. Eles vão lá e vendi de novo (PBCLMVF07)

2. envolve acréscimo de segmentos sem mudanças vocálicas na forma plural;

(5) a. Foi o meus primo, meus tio, minhas tia (PBRIMJF01)

b. Os primeiros europeus a vir pra cá foram os espanhóis que aportaram aqui (PBRIMJS02)

3. envolve acréscimos de segmentos e mudanças diversas na forma plural: mudanças vocálicas na desinência, mudanças na raiz, e até mudanças completas.

(6) a. Muitas pessoas vieram pra cá (PBRIMJS02)

b. Veio pessoas doentes, idosas (PBRIMJS02)

Muitos estudos (cf. LEMLE e NARO, 1977; NARO, 1981; RODRIGUES, 1987; SCHERRE e NARO, 1997; MONGUILHOTT, 2001; SILVA, 2003; PEREIRA, 2004;

\footnotetext{
${ }^{2}$ A codificação refere-se: à amostra do nosso corpus (PB - Português do Brasil), à localidade em que a entrevista foi realizada (RI: Ribeirão da Ilha, IN: Ingleses, CL: Costa da Lagoa, RC: Região Central), ao sexo do informante (F: feminino, M: masculino), à idade do informante (J - 15 a 36 anos, V - 45 a 76 anos), à escolaridade do informante (F: fundamental - de $1^{\text {a }}$. a $9^{\mathrm{a}}$ série, S: superior - do 12 ano ao superior concluído com mestrado) e ao número de identificação de cada informante na amostra.
} 
CARDOSO, 2005) já atestaram a relevância deste grupo de fatores indicando que formas mais salientes tendem a ser mais marcadas do que as menos salientes, i.e., as oposições mais salientes, sendo mais perceptíveis, aumentam a probabilidade de ocorrência da variante explícita de plural. Partindo dos resultados desses estudos, a expectativa para nossa amostra era de que as formas mais salientes também favorecessem a presença da marca de concordância na terceira pessoa do plural.

Nossos resultados vêm corroborar os resultados desses estudos com a oposição acentuada favorecendo a presença de marcas explícitas de plural nos verbos, contrário à oposição não-acentuada, com maiores probabilidades de marcas zero de concordância, como podemos observar na tabela 1 a seguir.

\begin{tabular}{lccc}
\hline \multicolumn{1}{c}{ Nível 1: Oposição não-acentuada } & Apl/Total $^{3}$ & $\%$ & PR $^{\mathbf{4}}$ \\
\hline $\begin{array}{l}\text { a. não envolve mudança na qualidade da } \\
\text { vogal na forma plural }\end{array}$ & $19 / 89$ & $21 \%$ & .04 \\
$\begin{array}{l}\text { b. envolve mudança na qualidade da } \\
\text { vogal na forma plural }\end{array}$ & $274 / 324$ & $84 \%$ & .50 \\
$\begin{array}{l}\text { c. envolve acréscimo de segmentos na } \\
\text { forma plural }\end{array}$ & $48 / 51$ & $94 \%$ & .74 \\
$\quad \begin{array}{l}\text { Nível 2: Oposição acentuada } \\
\quad \text { envolve apenas mudança na }\end{array}$ & Apl/Total & $\%$ & PR \\
$\begin{array}{l}\text { qualidade da vogal na forma plural } \\
\text { b. envolve acréscimo de segmentos sem } \\
\text { mudanças vocálicas na forma plural }\end{array}$ & $73 / 87$ & $83 \%$ & .48 \\
$\begin{array}{l}\text { c. envolve acréscimos de segmentos e } \\
\text { mudanças diversas na forma plural }\end{array}$ & $162 / 175$ & $94 \%$ & .74 \\
\hline \multicolumn{1}{c}{ Total } & $92 \%$ & .69 \\
\hline
\end{tabular}

\footnotetext{
Tabela 1: Frequência e probabilidade de CV no PB de Florianópolis/SC, segundo a variável saliência fônica (Fonte: MONGUILHOTT, 2009, p. 116)
}

Verificamos, a partir dos resultados apontados na tabela 1, que os fatores pertencentes ao nível 1, oposição não-acentuada apresentaram uma escala hierárquica crescente de acordo com o aumento do grau de saliência perceptível. Na categoria a temos $21 \%$ de marcação da CV e .04 de peso relativo, na categoria b $84 \%$ e .50 e na c $94 \%$ e .74 de peso relativo.

No nível 2, a hierarquia não obedeceu a mesma ordem do nível 1, tendo uma pequena alteração entre as categorias b e c. A categoria a apresentou $83 \%$ de marcação da CV e .48 de peso relativo, a categoria b $94 \%$ e .74 e a c $92 \%$ de marcação e .69 de peso relativo.

É inegável que o nível 2, nos resultados gerais, apresenta maior probabilidade de aplicação da regra de concordância verbal em relação ao nível 1, como a tabela 2 a seguir

\footnotetext{
${ }^{3}$ A aplicação da regra refere-se às marcas explícitas de concordância no verbo, pois estas marcas sobressaíramse em relação às marcas zero. Dos 794 dados coletados do PB, 640 apresentaram marcas explícitas de concordância.

${ }^{4} \mathrm{PR}$ significa peso relativo.
} 
confirma, feita a partir de uma rodada estatística em que os fatores do nível 1 estão amalgamados, assim como os fatores do nível 2.

\begin{tabular}{lccc}
\hline \multicolumn{1}{c}{ Saliência Fônica } & Apl/Total & \% & PR \\
\hline Nível 1: Oposição não-acentuada & $341 / 464$ & $73 \%$ & .35 \\
Nível 2: Oposição acentuada & $299 / 330$ & $90 \%$ & .70 \\
\hline \multicolumn{1}{c}{ Total } & $\mathbf{6 4 0 / 7 9 4}$ & $\mathbf{8 0 \%}$ &
\end{tabular}

\section{Tabela 2: Frequência e probabilidade de CV no PB de Florianópolis/SC, segundo a variável saliência fônica com amálgama dos fatores do nível 1 e nível 2 (Fonte: MONGUILHOTT, 2009, p.117)}

\subsubsection{Paralelismo Formal}

Controlamos o paralelismo formal no nível clausal com o intuito de atestar se existe correlação entre o tipo de marca existente no sujeito e o tipo de marca existente no verbo, ou seja, se marcas explícitas de plural no sujeito levam à presença de marcas de plural no verbo e se o sujeito com marca zero de plural influencia a marca zero de plural no verbo.

Subdividimos este grupo nos seguintes fatores:

a. presença da forma de plural explícita no último (ou único) elemento

(7) As crianças gostam de brincar (PBRIFVS02);

b. presença da forma de plural zero no último elemento

(8) Os homi $\varnothing$ ia assim tarrafeá (PBINFVF02);

c. presença de numeral terminado em /s/ no último elemento

(9) Os dois só estudu (PBINFVS06);

d. presença de numeral não terminado em /s/ no último elemento

(10) Na Costa aqui estudou parece uns cinco só na Lagoa (PBCLMVF03);

e. sujeito nulo com sujeito anafórico com presença da forma de plural explícita no último (ou único) elemento

(11) Todas as minhas amigas namoravam e $\varnothing$ vinham às festas aqui (PBRIFVS05);

f. sujeito nulo com sujeito anafórico com presença da forma de plural zero no último elemento

(12) Os neto $\varnothing$ dele chamava ele de tolo, $\varnothing$ dizia: ah, o vô é tolo! (PBCLMVF03);

g. sujeito nulo com sujeito anafórico com presença de numeral terminado em /s/ no último elemento

(13) Tem dois ali que tão na biblioteca, $\varnothing$ tão fazendo trabalho (PBRIMJF09); 
h. sujeito nulo com sujeito anafórico com presença de numeral não terminado em /s/ no último elemento ${ }^{5}$

A nossa hipótese contempla o princípio geral do paralelismo: marcas levam a marcas, zeros levam a zeros.

Esperávamos que, tanto no sujeito preenchido, quanto no sujeito nulo com sujeito anafórico, quando o último elemento do sujeito apresentasse marca explícita de plural, o verbo correspondente tenderia a exibir a marca de plural, e se o último elemento do sujeito apresentasse zero plural, o verbo correspondente tenderia também a exibir zero plural (cf. SCHERRE e NARO, 1993; MONGUILHOTT, 2001; PEREIRA, 2004; CARDOSO, 2005).

Em relação à presença de numeral, acreditávamos que se o último elemento do sujeito, ou o sujeito anafórico, no caso de sujeito nulo, fosse um numeral terminado em /s/ haveria uma tendência maior para existir marca formal de plural no verbo, diferentemente dos numerais sem /s/, que deveriam influenciar na não marcação da concordância.

Nossos resultados revelam que o paralelismo formal, no nível clausal, mostrou-se bastante significativo na análise do Goldvarb, sendo o segundo grupo selecionado como estatisticamente relevante. Os resultados confirmam parcialmente nossas hipóteses. Como podemos observar na tabela 3, a marcação da concordância foi maior para os fatores presença da forma de plural explícita no último elemento ( $86 \%$ de frequência e .60 de peso relativo) e sujeito nulo com anafórico com presença da forma de plural explícita (87\% de frequência e .66 de peso relativo).

Tais resultados confirmam resultados de outros estudos com diferentes amostras do PB (SCHERRE e NARO, 1993; MONGUILHOTT, 2001; SILVA, 2003; PEREIRA, 2004; CARDOSO, 2005)

\begin{tabular}{|c|c|c|c|}
\hline Paralelismo Formal & Apl/Total & $\%$ & $\mathbf{P R}$ \\
\hline $\begin{array}{l}\text { Presença da forma de plural explícita } \\
\text { no último elemento }\end{array}$ & $418 / 483$ & $86 \%$ & .60 \\
\hline $\begin{array}{l}\text { Presença de numeral no último } \\
\text { elemento }\end{array}$ & $20 / 33$ & $60 \%$ & .13 \\
\hline $\begin{array}{l}\text { Presença da forma zero de plural no } \\
\text { último elemento }\end{array}$ & $52 / 100$ & $52 \%$ & .10 \\
\hline $\begin{array}{c}\text { Sujeito nulo com anafórico com } \\
\text { presença da forma de plural explícita }\end{array}$ & $128 / 148$ & $87 \%$ & .66 \\
\hline $\begin{array}{l}\text { Sujeito nulo com anafórico com } \\
\text { presença de numeral terminado em } \\
\text { /s/ no último elemento }\end{array}$ & $4 / 5$ & $80 \%$ & .58 \\
\hline $\begin{array}{l}\text { Sujeito nulo com anafórico com } \\
\text { presença da forma de zero plural }\end{array}$ & $17 / 25$ & $68 \%$ & .29 \\
\hline Total & $640 / 794$ & $80 \%$ & \\
\hline
\end{tabular}

Tabela 3: Frequência e probabilidade de CV no PB de Florianópolis/SC, segundo a variável paralelismo formal (Fonte: MONGUILHOTT, p. 121

\footnotetext{
${ }^{5}$ Não foram encontrados dados na amostra para este fator.
} 
Nossas expectativas também se confirmaram em relação aos fatores presença da forma zero de plural no último elemento e sujeito nulo com anafórico com presença da forma de zero plural, já que ambos os fatores tenderam à menor marcação da $\mathrm{CV}$, com resultados de $52 \%$ de frequência e .10 de peso relativo e $68 \%$ de frequência e .29 de peso relativo, respectivamente.

Quanto aos fatores presença de numeral terminado em /s/ e não terminado em /s/ no último elemento, os resultados foram amalgamados em função de seus índices de frequência, bem como de seu comportamento, mostrarem-se uniformes quando da presença de outros fatores ${ }^{6}$. Para esse grupo de fatores, nossas expectativas não se confirmaram, pois esperávamos maior marcação da CV. Nossos resultados apontam para uma marcação próxima da marcação do fator presença da forma zero de plural no último elemento, com $60 \%$ de frequência e .13 de peso relativo.

Já em relação ao sujeito nulo com anafórico com presença de numeral terminado em /s/ no último elemento, nossa hipótese se confirmou, já que os resultados apontam esse fator como favorecedor da marcação da CV com $80 \%$ de frequência e .58 de peso relativo. Para o fator sujeito nulo com presença de numeral não terminado em /s/, não obtivemos dados.

Embora os resultados em relação ao fator presença de numeral no último elemento não tenham confirmado nossa hipótese, os resultados gerais obtidos para esta amostra do PB vêm confirmar o princípio do paralelismo de "formas gramaticais particulares ocorrerem juntas" (SCHERRE, 1998, p.42). Acreditamos que esta repetição apresenta caráter mecânico; como Scherre (1998, p.49) aponta, diversos estudos variacionistas que controlaram o paralelismo (WEINER e LABOV, 1981; BRAGA, 1986; SCHIFFRIN, 1981; TANNEN, 1998) "concluíram que pode haver a repetição meramente mecânica".

\subsubsection{Posição do sujeito em relação ao verbo}

O português é uma língua do tipo Sujeito-Verbo-Objeto que admite variação; por isso, o SN pode aparecer posposto ao verbo. Dessa forma, para esse grupo de fatores, consideramos a anteposição ou a posposição do sujeito:

- SN V anteposição

(14) Eles moru lá na cidade (PBRIMJF09)

- V SN posposição

(15) Mora três lá perto da minha casa (PBINFVF02)

Baseando-nos em resultados de trabalhos empíricos, esperamos que haja enfraquecimento da concordância com o SN pós-verbal, como veremos a seguir.

Lemle e Naro (1977) apontam que a probabilidade de concordância verbal com SNs pós-verbais é muito menor do que com SNs pré-verbais, independendo até mesmo do nível de escolaridade a que pertence o falante. Lira (1986) também comprova o alto índice de ausência

\footnotetext{
${ }^{6} \mathrm{Na}$ rodada sem amálgama dos fatores, obtivemos os seguintes resultados: presença de numeral terminado em /s/ no último elemento $-18 / 28=64 \%$ e .14 de peso relativo; presença de numeral não terminado em /s/ no último elemento $-2 / 5=40 \%$ e .06 de peso relativo.
} 
de concordância com SNs pospostos em seus resultados: probabilidade de .62 de ausência de concordância para apenas .38 de presença.

Rodrigues (1987), atestou, em seu estudo que o sujeito posposto influencia fortemente a não concordância com $97 \%$ de frequência e .88 de peso relativo, diferentemente do sujeito anteposto, com $76 \%$ de frequência e .31 de peso relativo, assim também como o sujeito distante do verbo $78 \%$ de frequência e .45 de peso relativo.

Berlinck (1988) também apresenta resultados que apontam maior tendência aos SNs pospostos desencadearem menor concordância. Em seus resultados, 94\% dos SNs pospostos apresentam ausência de concordância para apenas $20 \%$ de presença, um percentual bastante significativo. Vale lembrar que seus dados são de informantes de nível universitário. A autora diz que essa associação de $\mathrm{SN}$ posposto e ausência de concordância têm servido de argumento favorável à tese do caráter menos 'subjetivo' do sujeito.

Pontes (1986) discute, em seu trabalho, o estatuto de sujeito do SN posposto evidenciando que este tipo de sujeito apresenta características de objeto ${ }^{7}$ (posição VSN, [concordância]).

A autora ressalta, a partir de um teste feito com alguns estudantes da Faculdade de Letras da UFMG, que o SN posposto é encarado, muitas vezes, como objeto por uma parcela significativa de falantes que, por conseqüência, apresentam dificuldade na marcação da concordância com esses tipos de SNs.

Scherre e Naro (1997) apresentam resultados que apontam para o fato de que, quando o sujeito está em uma posição mais à esquerda e mais próximo do verbo, existe maior probabilidade de favorecimento da ocorrência da variante explícita, enquanto a posição à direita e o distanciamento em relação ao verbo a desfavorecem, independentemente do grau de escolaridade dos falantes.

Monguilhott (2001) evidencia em seus resultados o sujeito anteposto ao verbo como favorecedor da concordância com $84 \%$ de frequência e .78 de peso relativo, enquanto o sujeito posposto ao verbo como favorecedor da não concordância com $52 \%$ de frequência e .17 de peso relativo.

Coelho e Monguilhott (2007) atestam, em seu trabalho, que a ordem VS condiciona a não marcação da concordância nos verbos, corroborando a tese do caráter não subjetivo do argumento que se posiciona à direita do verbo.

Coelho, Monguilhott e Martins (2008) apresentam resultados de amostras diacrônicas em que há marcação de $100 \%$ nos casos de verbos com sujeito invertido no século XIX. Já no século $\mathrm{XX}$, a frequência de marcação é de $85 \%$. Os autores evidenciam que os resultados refletem a relação que há entre marcação da $\mathrm{CV}$ e ordem $\mathrm{SV}$; como a ordem $\mathrm{SV}$ está cada vez mais enrijecida no $\mathrm{PB}$, há menos marcação da $\mathrm{CV}$ com sujeito invertido no PB atual.

Partindo destas evidências, acreditávamos que o $\mathrm{SN}$, quando posposto ao verbo, apresentaria forte tendência à variante zero de plural nos verbos.

A posição do sujeito em relação ao verbo foi o terceiro grupo de fatores selecionado pelo Goldvarb. Podemos observar, através da tabela 4, que a probabilidade de aplicação da regra de concordância foi maior quando o sujeito estava anteposto ao verbo, com $84 \%$ de frequência e .57 de peso relativo, distanciando-se significativamente da posposição do sujeito,

\footnotetext{
${ }^{7}$ O SN posposto, conforme Pontes (1986), mesmo apresentando características de objeto não admite cliticização como em: (1) A Sarinha tá nascendo dente; (2)*A Sarinha nasceu-o.
} 
com 34\% de frequência e .08 de peso relativo, confirmando, dessa forma, nossa hipótese e corroborando resultados de alguns estudos do PB (LEMLE e NARO, 1977; PONTES, 1986; RODRIGUES, 1987; BERLINCK, 1988; SCHERRE e NARO, 1997; MONGUILHOTT, 2001; SILVA, 2003; CARDOSO, 2005).

\begin{tabular}{cccc}
\hline Posição & Apl/Total & \% & PR \\
\hline SN anteposto & $464 / 546$ & $84 \%$ & .57 \\
SN posposto & $23 / 67$ & $34 \%$ & .08 \\
\hline Total & $\mathbf{4 8 7 / 6 1 3 ^ { 8 }}$ & $\mathbf{7 9 \%}$ &
\end{tabular}

Tabela 4: Frequência e probabilidade de CV no PB de Florianópolis/SC, segundo a variável posição do sujeito em relação ao verbo (Fonte: MONGUILHOTT, p. 123)

Nossos resultados indicam, conforme apontam alguns estudos, que parece que o sujeito quando posposto ao verbo passa a ser encarado como objeto pelo falante que não aplica a regra de concordância, já que não o considera sujeito da sentença.

\subsubsection{Traço humano no sujeito}

Controlamos, neste grupo de fatores, os traços do SN do tipo [+/-humano]:

- $\mathrm{SN}[+$ humano]

(16) Eles não trabalham com isso (PBRCMJS16);

- $\mathrm{SN}$ [-humano]

(17) Existe muitas barreiras, muitas dificuldades para que os jovens possam desenvolver atividades esportivas (PBRIMJS04)

Em relação a esse grupo de fatores, esperávamos que, quando o traço do sujeito fosse [+humano], a probabilidade de marcas de concordância no verbo seria maior, já que ele se caracterizaria mais prototipicamente como sujeito, diferentemente do SN com traço [humano], que tenderá a desencadear menos marcas de concordância no verbo em função de, numa escala de "sujeitividade", apresentar-se menos "sujeito".

O grupo de fatores traço humano no sujeito foi selecionado como estatisticamente relevante em quinto lugar.

Confirmando nossa hipótese e também resultados de outras pesquisas com amostras do PB (SCHERRE e NARO, 1998; MONGUILHOTT, 2001; SILVA, 2003; PEREIRA, 2004; CARDOSO, 2005), quando a sentença possuía um SN [+humano] a probabilidade à

\footnotetext{
${ }^{8}$ Vale observar que, para esse grupo de fatores, temos um total de 613 dados, pois os dados de sujeito nulo não puderam ser considerados.
} 
concordância verbal foi maior do que em sentenças com SNs [-humanos], como mostram os resultados na tabela 5 .

\begin{tabular}{cccc}
\hline Traço humano no sujeito & Apl/Total & $\%$ & PR \\
\hline SN [+humano] & $588 / 701$ & $83 \%$ & .56 \\
SN [-humano] & $52 / 93$ & $55 \%$ & .12 \\
\hline Total & $\mathbf{6 4 0 / 7 9 4}$ & $\mathbf{8 0 \%}$ &
\end{tabular}

\section{Tabela 5: Frequência e probabilidade de CV no PB de Florianópolis/SC, segundo a variável traço humano no sujeito (Fonte: MONGUILHOTT, p. 124)}

\subsection{Variáveis Sociais}

Dentre as variáveis sociais controladas, somente a variável idade/escolaridade ${ }^{9}$ foi selecionada como estatisticamente relevante pelo Goldvarb. A variável foi selecionada em quarto lugar. Em relação a este grupo de fatores, controlamos as seguintes faixas etárias e níveis de escolaridade:

- 04 falantes com idade entre 15 e 36 anos com ensino fundamental (da $4^{\mathrm{a}}$. série completa a $9^{\text {a }}$. série completa) - jovem/ensino fundamental;

- 04 falantes com idade entre 22 e 33 anos com ensino superior concluído - jovem/ensino superior;

- 04 falantes com idade entre 48 e 74 anos com ensino fundamental (de $1^{\mathrm{a}}$. a $4^{\mathrm{a}}$. série incompleta a $7^{\text {a }}$. série completa) - velho/ensino fundamental;

- 04 falantes com idade entre 45 e 76 anos com ensino superior concluído - velho/ensino superior.

Nossas hipóteses em relação às duas faixas etárias controladas, jovens e velhos, relacionaram-se à diazonalidade. Acreditávamos que os jovens da zona não urbana preservariam mais as marcas de $\mathrm{CV}$ do que os velhos desta mesma zona. Já no que se refere à zona urbana, acreditávamos que os mais velhos preservassem mais a $\mathrm{CV}$.

Nossa expectativa, em relação à zona não urbana, baseou-se em Baxter (1995) e Lucchesi (2006). Baxter, citando o trabalho de Bortoni (1985), aponta que, em dialetos rurais, os jovens usam mais marcas de plural do que os falantes mais velhos (p.85). Lucchesi salienta tal relação, baseando-se nos resultados de Nina (1980), Vieira (1997) e Silva (2003). O autor aponta que a marcação da CV aumenta conforme a idade do falante diminui. Em relação à zona urbana, baseamo-nos também em Lucchesi (2006), que evidencia, a partir do trabalho de Graciosa (1991), que há queda na marcação da CV na fala dos mais jovens.

No que se refere à escolaridade, esperávamos que, quanto maior o nível de escolaridade, maior seria a probabilidade de o falante utilizar marcas mais formais, no caso do nosso estudo a marcação da concordância verbal, pois a escola é um dos ambientes que

\footnotetext{
${ }^{9}$ Os grupos de fatores idade e escolaridade foram controlados conjuntamente.
} 
privilegia a norma linguística utilizada na escrita e, de acordo com estudos variacionistas envolvendo a variável anos de escolarização, existe correlação entre formas linguísticas consideradas padrão (ensinadas na escola e reforçadas em outros ambientes - como TV, jornais) e maior escolaridade.

Os resultados mostram que, tanto no nível superior, quanto no nível fundamental, os mais jovens tendem a preservar as marcas de CV do que os mais velhos, como podemos verificar na tabela 6 , a seguir.

\begin{tabular}{cccc}
\hline Idade/escolaridade & Apl/Total & \% & PR \\
\hline Jovem/ensino superior & $225 / 252$ & $89 \%$ & .74 \\
Velho/ensino superior & $172 / 195$ & $88 \%$ & .52 \\
Jovem/ensino fundamental & $115 / 158$ & $72 \%$ & .32 \\
Velho/ensino fundamental & $128 / 189$ & $67 \%$ & .28 \\
\hline Total & $\mathbf{6 4 0 / 7 9 4}$ & $\mathbf{8 0 \%}$ & \\
\hline
\end{tabular}

\section{Tabela 6: Frequência e probabilidade de CV no PB de Florianópolis/SC, segundo a variável idade/escolaridade (Fonte: MONGUILHOTT, p. 130)}

Os resultados apontam, ainda, que os informantes mais escolarizados, independentemente da idade, preservam as marcas de concordância verbal, correspondendo, desta forma, aos resultados de outros estudos que controlaram a escolaridade em amostras do PB (SCHERRE e NARO, 1997; MONGUILHOTT, 2001).

\subsection{Variáveis geográficas}

Dentre as variáveis geográficas controladas, a diatopia foi selecionada como estatisticamente relevante em sexto lugar.

A cidade de Florianópolis possui muitos bairros, sendo que a maioria se localiza na ilha, além de outros na parte continental. Em nosso estudo, optamos por selecionar os quatro pontos a serem investigados na ilha, localizados em áreas distintas, por julgarmos representativos da comunidade de fala florianopolitana ${ }^{10}$.

O que podemos observar nos resultados da tabela 7, abaixo, é que a região central foi a que mais preservou as marcas de CV e a Costa da Lagoa a que menos preservou.

\footnotetext{
${ }^{10}$ Para definirmos Florianópolis como uma comunidade de fala, levamos em conta os critérios apontados por Guy $(2000,2001)$.
} 


\begin{tabular}{cccc}
\hline Diatopia & Apl/Total & \% & PR \\
\hline Ribeirão da Ilha & $155 / 188$ & $82 \%$ & .48 \\
Costa da Lagoa & $179 / 243$ & $73 \%$ & .32 \\
Ingleses & $134 / 172$ & $77 \%$ & .33 \\
Região Central & $172 / 191$ & $90 \%$ & .83 \\
\hline Total & $\mathbf{6 4 0 / 7 9 4}$ & $\mathbf{8 0 \%}$ & \\
\hline
\end{tabular}

\footnotetext{
Tabela 7: Frequência e probabilidade de CV no PB em Florianópolis/SC, segundo a variável diatopia (Fonte: MONGUILHOTT, p. 139)
}

O que esperávamos para este grupo de fatores era que as localidades que fazem parte da zona urbana, Região Central e Ingleses, preservassem mais a CV. No caso da Região Central foi o que aconteceu, mas não nos Ingleses. O que parece explicar os resultados é que, embora o bairro dos Ingleses tenha se urbanizado nos últimos tempos com o crescente comércio em função do turismo, os nativos continuam convivendo muito mais entre eles, preservando, desta forma, as marcas menos urbanas.

Em relação ao Ribeirão da Ilha e à Costa da Lagoa, nossas expectativas se confirmaram, já que os bairros considerados não urbanos, em função do distanciamento com a região central da cidade, preservaram menos as marcas de CV do que a Região Central. Considerando os dois bairros, os resultados confirmam o que de fato também era esperado. Embora sempre que vá se falar de interior da Ilha de Santa Catarina, em bairro típico da cidade, em "falar manezinho", se faça referência primeiramente ao Ribeirão da Ilha, a Costa da Lagoa é caracterizadamente mais rural do que o Ribeirão, em função principalmente do seu isolamento, só se chega lá de barco, as pessoas todas se conhecem, o que já não ocorre no Ribeirão que tem estradas e muitas pessoas de fora o ano inteiro circulando, em função principalmente da maricultura.

\section{CONSIDERAÇÕES FINAIS}

Neste artigo, procuramos apresentar os resultados da investigação e do mapeamento do fenômeno da concordância verbal de terceira pessoa do plural na fala de informantes florianopolitanos em uma amostra sincrônica do século XXI, resultado da minha tese de doutorado.

No que se refere aos resultados da análise estatística, estes confirmam nossa hipótese indicando que a variação do fenômeno da concordância verbal é condicionada muito mais por grupos de fatores linguísticos do que extralinguísticos.

Constatamos que as variáveis linguísticas saliência fônica e paralelismo formal mostraram-se as mais significativas no condicionamento da $\mathrm{CV}$. As variáveis traço humano no sujeito e posição do sujeito em relação ao verbo também foram selecionadas. Considerando as variáveis linguísticas selecionadas, temos o seguinte contexto desfavorecendo a marcação da CV: verbo menos saliente (oposição não-acentuada), presença de forma zero de plural no último elemento, sujeito posposto ao verbo, com traço [- humano].

Já em relação às variáveis extralinguísticas, duas delas foram selecionadas: idade/escolaridade e diatopia. Considerando o contexto extralinguístico temos menos 
marcação da CV na fala de informantes mais velhos com ensino fundamental e informantes nativos da comunidade da Costa da Lagoa.

Partindo da abordagem teórico-metodológica da TVML e da Dialetologia Pluridimensional, acreditamos que essa pesquisa, resultado de parte das investigações que realizei no meu doutorado e que estão publicadas na minha tese, tenha contribuído para a descrição do português falado na ilha de Florianópolis, à medida que confirmamos resultados de estudos sobre a concordância verbal de terceira pessoa do plural com outras amostras do $\mathrm{PB}$, bem como investigamos comunidades nunca antes estudadas.

\section{REFERÊNCIAS}

BAXTER, A. N. Transmissão geracional irregular na história do português brasileiro divergências nas vertentes afro-brasileiras. Revista Internacional de Língua Portuguesa. n.14, dez. 1995.

BELlMANN, G. Variação e devariação. Cadernos de Tradução do Instituto de Letras da UFRGS. Porto Alegre, n. 4, p. 7-20, 1999.

BERLINCK, R. A ordem V SN no português do Brasil: sincronia e diacronia. Campinas: UNICAMP, 1988. [Dissertação de Mestrado].

CARDOSO, C. R. Variação da concordância verbal no indivíduo: um confronto entre o linguíístico e o estilístico. Brasília: UNB, 2005. [Dissertação de Mestrado].

LABOV, W. Padrões Sociolingüísticos. Tradução: M. Bagno; M. M. P. Scherre; C. R. C. São Paulo: Parábola Editorial, 2008 [1972].

LEMLE, M.; NARO, A. J. Competências básicas do português. Relatório final de pesquisa apresentado às instituições patrocinadoras Fundação Movimento Brasileiro de Alfabetização (Mobral) e Fundação Ford, 1977.

LIRA, S. de A. Subject postposition. Documentação de Estudos em Lingüística Teórica e Aplicada, 2(1): 17-36, 1986.

LUCCHESI, D. Parâmetros sociolingüísticos do Português do Brasil. Revista da Abralin, vol. 5, no. 1 e 2, dez. 2006.

MONGUILHOTT, I. de O. e S. Variação na concordância verbal de terceira pessoa do plural na fala dos florianopolitanos. Florianópolis: UFSC, 2001. [Dissertação de Mestrado].

. Estudo sincrônico e diacrônico da concordância verbal de terceira pessoa do plural no PB e no PE. Florianópolis: UFSC, 2009. [Tese de Doutorado].

NARO, A. J. The social and structural dimensions of a syntatic change. Language, 57 (1): 6398, 1981.

NARO, A. J.; SCHERRE, M. M. P. Origens do Português Brasileiro. São Paulo: Parábola Editorial, 2007.

PEREIRA, D. C. Concordância verbal na língua falada nas trilhas das bandeiras paulistas. São Paulo: USP, 2004. [Dissertação de Mestrado].

PONTES, E. S. L. Sujeito: da sintaxe ao discurso. São Paulo: Ática, 1986. 
RADTKE, E.; THUN, H. Nuevos caminos de la geolinguística románica. Un balance. In: RADTKE, E.; THUN, H. (orgs.). Neue Wege der Romanischen Geolinguistik. Akten des Symposiums Empirischen Dialektologie (Heidelberg/Mainz, 21-24.10.1991), Kiel: Westensee-Verlag, p. 25-49, 1996.

ROBINSON, J.; LAWRENCE, H.; TAGLIAMONTE, S. GoldVarb 2001: a multivariate analysis for Wplication Windows. Disponível http://www.york.ac.uk/depts/lang/webstuff/goldvarb.

RODRIGUES, A. C. de S. A concordância verbal no português popular em São Paulo. São Paulo: PUC-SP, 1987. [Dissertação de Mestrado].

SCHERRE, M. M. P. Paralelismo lingüístico. Revista de Estudos da Linguagem. Belo Horizonte, Faculdade de Letras da UFMG. 7(2): 29-59 jul/dez de 1998.

Duas dimensões do paralelismo formal na concordância verbal no português popular do Brasil. D.E.L.T.A., 9(1): 1-14, 1993.

A concordância de número no Português do Brasil: um caso de variação inerente. In: HORA, D. (org.) Diversidade lingüística no Brasil. João Pessoa: Idéia, 1997.

Restrições sintáticas e semânticas no controle da concordância verbal em português. Fórum Lingüístico. 1 (45-71). Pós-Graduação em Linguística, UFSC. Florianópolis, 1998.

THUN, H. La geolingüística como lingüística variacional general (com ejemplos del Atlas lingüístico Diatópico y Diastrático del Uruguay). In: International Congress of Romance Linguistics and Philology. Atti del XXI Congresso Internazionale di Lingüística e Filologia Romanza. Org. G. Ruffino. Tübingen: Niemeyer, p. 701-729, 1998.

WEINREICH, U.; LABOV, W.; HERZOG, M. Fundamentos empíricos para uma teoria da mudança lingüística. Tradução: M. Bagno. São Paulo: Parábola Editorial, 2006 [1968].

Data de submissão: 15/05/2014

Data de aceite: 04/08/2014 